\title{
Limited Contribution of Primary Motor Cortex in Eye-Hand Coordination: A TMS Study
}

\author{
- $J a m e s$ Mathew, ${ }^{1}$ Alexandre Eusebio, ${ }^{1,2}$ and ${ }^{-F}$ Frederic Danion ${ }^{1}$ \\ ${ }^{1}$ Aix Marseille Université, Centre National de la Recherche Scientifique, Institut de Neurosciences de la Timone UMR 7289, 13385 Marseille, France, and \\ ${ }^{2}$ Assistance Publique des Hopitaux de Marseille, Service de Neurologie et Pathologie du Mouvement, Hôpital de la Timone, 13385 Marseille, France
}

The ability to track a moving target with the eye is substantially improved when the target is self-moved compared with when it is moved by an external agent. To account for this observation, it has been postulated that the oculomotor system has access to hand efference copy, thereby allowing to predict the motion of the visual target. Along this scheme, we tested the effect of transcranial magnetic stimulation (TMS) over the hand area of the primary motor cortex (M1) when human participants (50\% females) are asked to track with their eyes a visual target whose horizontal motion is driven by their grip force. We reasoned that, if the output of M1 is used by the oculomotor system to keep track of the target, on top of inducing short latency disturbance of grip force, single-pulse TMS should also quickly disrupt ongoing eye motion. For comparison purposes, the effect of TMS over M1 was monitored when subjects tracked an externally moved target (while keeping their hand at rest or not). In both cases, results showed no alterations in smooth pursuit, meaning that its velocity was unaffected within the $25-125 \mathrm{~ms}$ epoch that followed TMS. Overall, our results imply that the output of M1 has limited contribution in driving the eye motion during our eye-hand coordination task. This study suggests that, if hand motor signals are accessed by the oculomotor system, this is upstream of M1.

Key words: efference copy; eye tracking; eye-hand coordination; prediction; primary motor cortex; smooth pursuit; TMS

\section{Significance Statement}

The ability to coordinate eye and hand actions is central in everyday activity. However, the neural mechanisms underlying this coordination remain to be clarified. A leading hypothesis is that the oculomotor system has access to hand motor signals. Here we explored this possibility by means of transcranial magnetic stimulation (TMS) over the hand area of the primary motor cortex (M1) when humans tracked with the eyes a visual target that was moved by the hand. As expected, ongoing hand action was perturbed 25-30 ms after TMS, but our results fail to show any disruption of eye motion, smooth pursuit velocity being unaffected. This work suggests that, if hand motor signals are accessed by the oculomotor system, this is upstream of M1.

\section{Introduction}

Eye and hand are central effectors in everyday activities. Understanding how these two effectors are coordinated is fascinating both from a functional and theoretical perspective (Engel and Soechting, 2003; Crawford et al., 2004). Here we focus on a situation in which people track with their eyes a visual target that is

\footnotetext{
Received Feb. 28, 2017; revised Aug. 9, 2017; accepted Sept. 5, 2017.

Author contributions: J.M. and F.D. designed research; J.M., A.E., and F.D. performed research; J.M. and F.D. contributed unpublished reagents/analytic tools; J.M. and F.D. analyzed data; J.M., A.E., and F.D. wrote the paper.

This work was part of Innovative Training Network Perception and Action in Complex Environment, supported by the European Union's Horizon 2020 research and innovation program Marie Sklodowska-Curie Grant Agreement 642961 and French National Grant REM ANR-13-APPR-0008. This paper reflects only the authors' view and that the Research Executive Agency of the European Commission is not responsible for any use that may be made of the information it contains.

The authors declare no competing financial interests.

Correspondence should be addressed to Dr. Frederic Danion, Aix Marseille Université, Centre National de la

Recherche Scientifique, Institut de Neurosciences de la Timone, UMR 7289, 13385 Marseille, France. E-mail: frederic.danion@univ-amu.fr.

DOI:10.1523/JNEUROSCI.0564-17.2017

Copyright $\odot 2017$ the authors $\quad 0270-6474 / 17 / 379730-11 \$ 15.00 / 0$
}

moved by the hand. It is well established that smooth pursuit (SP) eye movements are substantially improved when the viewed target is moved by the subject's hand compared with when it is moved by an external agent as reflected by a higher SP gain, fewer saccades, and a shorter eye-target lag (Steinbach and Held, 1968; Angel and Garland, 1972; Gauthier et al., 1988; Vercher et al., 1995; Chen et al., 2016; Landelle et al., 2016). Furthermore, accurate SP of a self-moved target is possible in the absence of vision (Gauthier and Hofferer, 1976) and in deafferented patients (Vercher et al., 1996). To account for these observations, a leading hypothesis is that the oculomotor system benefits from hand motor signals (Steinbach and Held, 1968; Vercher et al., 1996). More specifically, it is suggested that the oculomotor system has access to an estimate of current hand position using predictive mechanisms combining hand efference copy and knowledge of hand-target dynamics (Scarchilli et al., 1999; Ariff et al., 2002; Vercher et al., 2003). Although attractive, direct neurophysiological evidence for this scheme still remains to be found. 


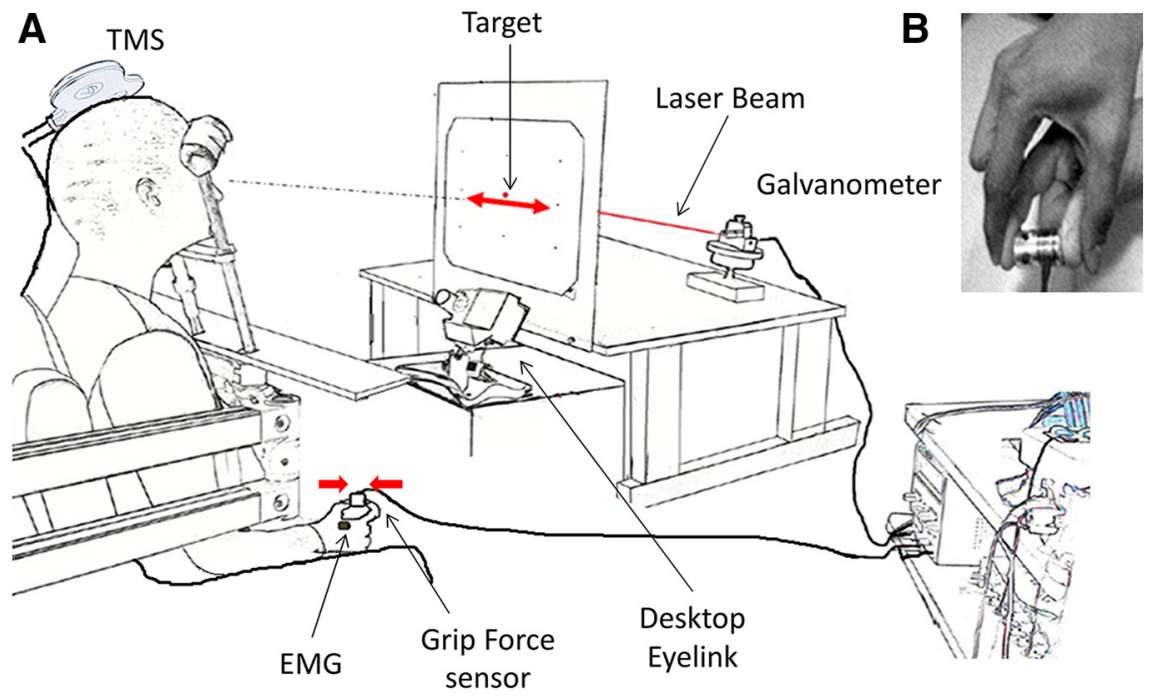

Figure 1. $\quad A$, Schematic drawing of the experimental setup. All parts of this figure were drawn by the authors. $B$, Photography relative to the EXT-TACTILE condition in which passive grip force modulation was generated via the experimenter (who is holding the participant's hand).

The goal of the present study was to investigate the contribution of the primary motor cortex (M1) into eye-hand coordination. This objective was motivated by several reports demonstrating intricate relationships between activity in M1 and the oculomotor system. First, it has been shown that transcranial magnetic stimulation (TMS) over M1 hand area (but not over M1 leg area) perturbs predictive gaze during observation of other's people doing manual actions (Elsner et al., 2013). Second, changes in corticospinal excitability at the level of M1 hand area have been demonstrated during ocular tracking (Maioli et al., 2007; Hiraoka et al., 2014) or when trying to stop impeding saccade (Wessel et al., 2013). Third, it was recently shown that lateralized readiness potential associated with hand movements is strongly predictive of SP when tracking a self-moved target (Chen et al., 2016), and it is generally assumed that lateralized readiness potential is generated in M1 (Coles, 1989); however, the causal relationship between lateralized readiness potential and SP remains to be established. Finally, the possibility that M1 contributes to an efference copy has been evoked in some reports (Scott, 2004; Voss et al., 2007; Witham et al., 2010) but dismissed in others (Chronicle and Glover, 2003; Voss et al., 2006; Timm et al., 2014); still, to our knowledge this issue has never been addressed in the context of coordinating multiple effectors.

Here, to determine whether there is a causal relationship between activity in M1 and SP during eye-hand coordination, we monitored the effects of TMS over M1 hand area when tracking with the eyes a self-moved target. We used the following rationale: if the output of M1 is used by the oculomotor system, in addition to motor evoked potentials (MEPs) perturbing hand actions, TMS should also induce short latency effects perturbing SP. Practically, subjects were asked to hold a force sensor and modulate grip force (GF) so as to move a target on a screen while concurrently keeping their eyes on the target. Because nonspecific effects of TMS on eye motion have been reported (XuWilson et al., 2011), the effect of TMS was also investigated during eye tracking tasks that did not involve eye-hand coordination. Finally, a subsidiary goal was to further document the effect of TMS on SP, which was found to be effective when applied over cortical areas, such as the frontal eye field (Gagnon et al., 2006; Nuding et al., 2009) or the cerebellum (Ohtsuka and
Enoki, 1998; Haarmeier and Kammer, 2010) but to our knowledge never explicitly tested over M1.

\section{Materials and Methods}

Participants. Twelve healthy right-handed volunteers (age: $27.6 \pm 8.3$ years, hereinafter mean \pm SD, range: $19-44$ years, 6 male) were recruited. A few days before the experiment, participants first received written and oral information about the TMS technique and underwent a brief examination by a neurologist to ensure that none of them had contraindications to TMS (Rossi et al., 2009). All participants gave written consent before participation and received $40 €$. The local ethics committee called Comité de Protection des Personnes Sud Méditerranée 1 approved the experimental paradigm (no. 2013-1346), which complied with the Declaration of Helsinki.

Data acquisition. The experimental setup, adapted from Landelle et al. (2016), is illustrated in Figure 1. Subjects were comfortably seated in a dark room facing a screen positioned on the frontal plane $57 \mathrm{~cm}$ away from the subject's eye. To minimize measurement errors, subjects' head movements were restrained by a chin rest and a padded forehead rest so that the eyes in primary position were directed toward the center of the screen. A mask was positioned under the participants' chin to block vision of their hands. In some of the experimental conditions (see below), participants were required to grasp with the right hand a force sensor (ELPM-T1M-25N, Entran) between the index finger and the thumb. The right forearm was resting over the subject's laps. The output of force sensor (i.e., GF) was sent to a multichannel signal conditioner (MSC12, Entran), then recorded at $1000 \mathrm{~Hz}$ with a resolution of $0.02 \mathrm{~N}$. Electromyographic activity was recorded from the first dorsal interosseous (FDI) at a $1000 \mathrm{~Hz}$ sampling frequency (Delsys Bagnoli). Electrodes were positioned over the belly tendon montage, and a Dermatrode selfadhering electrode was positioned on right olecranon elbow for ground.

The target was a red disk laser beam $\left(0.5^{\circ}\right.$ in diameter $)$ projected on the screen. The laser was moved by an optical scanner (GSI M2 series) servocontrolled by a PC. The delay in the servo-command was $<2 \mathrm{~ms}$. The optical scanner motion was restricted to one dimension so that the target moved only along the horizontal axis. Eye movements were recorded using an infrared video-based eye tracker (Eyelink Desktop-mounted system; SR Research). Horizontal and vertical positions of the right eye were recorded at a sampling rate of $1000 \mathrm{~Hz}$. Before each block of trials, we calibrated the output from the eye tracker by recording the raw eye positions as subjects fixated a grid composed of 9 known locations. The mean values during $1000 \mathrm{~ms}$ fixation intervals at each location were then used for converting off line raw eye tracker values to horizontal and vertical eye position in degrees of visual angles.

TMS hot spot search. A $70 \mathrm{~mm}$ figure-of-eight double coil connected to a Magstim Bistim2 magnetic stimulator (Magstim) was positioned tangentially to the scalp, oriented perpendicular to the central sulcus and $45^{\circ}$ angle to the interhemispheric fissure (Brasil-Neto et al., 1992; Mills et al., 1992). With the coil handle pointing laterally and caudally, a posterioranterior brain current through the precentral gyrus was induced (Wassermann et al., 2008). While the participant held a constant GF of $3 \mathrm{~N}$, the site at which the largest GF pulse elicited was determined. When this site was found we determined the active motor threshold (AMT) as the lowest intensity that could elicit noticeable changes in GF in 5 of 10 trials while maintaining a GF of $3 \mathrm{~N}$. The mean group AMT was $40.8 \pm 7.3 \%$ of maximum stimulator output (range: $33 \%-56 \%$ ). Subsequently, the intensity of TMS was raised so as to induce reliable $1 \mathrm{~N}$ GF pulses (while maintaining $3 \mathrm{~N}$ ). This procedure allowed normalizing the behavioral and visual effects of TMS across subjects. The corresponding mean group TMS intensity was $45.7 \pm 7.8 \%$, which corresponds to $\sim 110 \%$ of AMT. 
Before each TMS session, we ensured that the coil was still adequately positioned (i.e., giving rise to a $1 \mathrm{~N}$ increment in GF).

Experimental design. In all trials, subjects were instructed to track with their eyes a moving target on the screen as accurately as possible. Depending on the experimental condition, the motion of the target was driven either by the subjects themselves (SELF) or by an external agent (EXTERNAL). We propose to present first the SELF protocol in which subjects drove the target motion with the right hand through GF modulations. The mapping was chosen such that, when GF was $3 \mathrm{~N}$, the target was located at the center of the screen. When GF increased to $5 \mathrm{~N}$, the target moved $15^{\circ}$ to the right $(+)$, conversely when GF decreased to $1 \mathrm{~N}$ the target moved $15^{\circ}$ to the left $(-)$. Overall, the gain between GF and target position was $1 \mathrm{~N}$ for $7.5^{\circ}$. Subjects were encouraged to use the whole extent of the screen $\left( \pm 15^{\circ}\right)$ while making sure that the target did not fall outside of the screen boundaries. Subjects were asked to perform random oscillatory target movements (for a similar procedure, see Steinbach and Held, 1968; Angel and Garland, 1972; Landelle et al., 2016). The underlying motivation was to make target motion as unpredictable as possible when subsequently played back in the EXTERNAL conditions. To facilitate the production of random movements, a template was given during demonstration trials. During the experimental trials, we ensured that GF modulation led to a mean absolute target velocity close to $30 \%$ s: mean target velocity was computed online, and the experimenters provided some verbal feedback to the subject, such as "please move faster" or "please slow down," when necessary. This procedure ensured minimal changes in mean target velocity across subjects $(\mathrm{SD}=0.95 \%)$, experimental conditions $(\mathrm{SD}=1.16 \%$ ), and trials $(\mathrm{SD}=0.42 \%$ ).

A total of four conditions with a self-moved target were tested. These were the following. In the first one called SELF, the participants simply moved the target randomly with the hand and tracked it with the eyes. In the SELF-TMS condition, the task was similar but occasionally (4 times per trial) TMS pulses were triggered. Despite fast target jumps inherent to the effect of TMS on GF, subjects were encouraged to keep on tracking the target. The third condition (SELF-MIMIC) was similar to SELF, except that we occasionally ( 4 times per trial) induced some transient target jumps that mimicked those observed during SELF-TMS. These visual perturbations were accompanied by a TMS click from a coil positioned $10 \mathrm{~cm}$ above the scalp (SHAM TMS). This mimicking was possible thanks to a polynomial function (fifth order) derived from pilot studies $(N=5)$ that fitted TMS induced GF pulses between 30 and $230 \mathrm{~ms}$ after TMS. The underlying motivation for mimicking the effect of TMS was to investigate the effect of the visual perturbation and TMS click in the absence of TMS. As exposed in Figure $2 A$, this procedure was rather successful in that mean target trajectory in SELF-TMS and SELF-MIMIC were very similar. However, visual perturbations in SELF-MIMIC were less variable because we used the same polynomial function for all the participants. In the last condition (SELF-TMS-MASK), the procedure was similar to SELF-TMS, except that we manipulated visual feedback so as to mask the target jumps induced by TMS. To achieve this goal, we developed an algorithm to extrapolate the "intended" target trajectory for $200 \mathrm{~ms}$ based on its position and velocity just before the behavioral effect of TMS. Practically within the next $200 \mathrm{~ms}$, target velocity was decreased by $1 / 250$ of its initial value every millisecond. As shown in Figure $2 B$, this procedure was rather effective in that the resulting target trajectory was smooth (no more target jumps) and was very similar to the one observed during SELF for comparable time periods. This condition
B

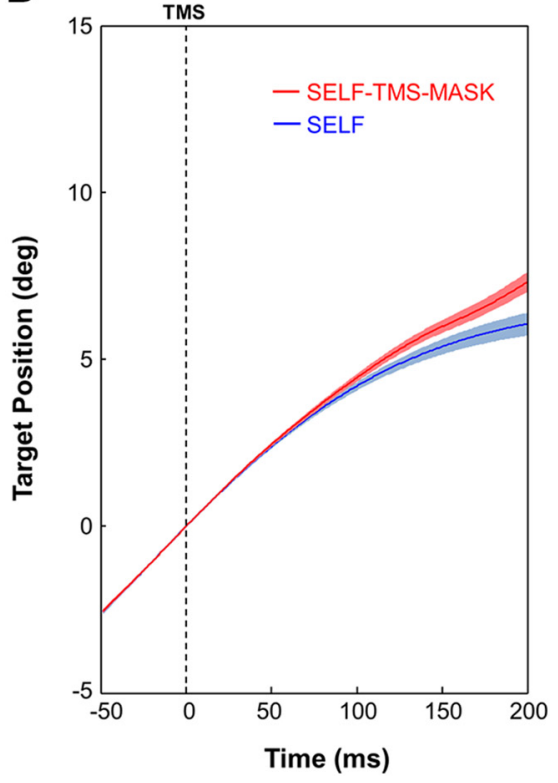
consequences.

Participants also had to perform trials under which target motion was externally driven (EXTERNAL). A total of four EXTERNAL conditions were tested. In the first one (EXT), target trajectories collected during SELF were played back in the same order. Each participant was presented their own trials (Angel and Garland, 1972; Landelle et al., 2016). This procedure allowed within-subject comparisons. During this condition, the right hand of the subject was relaxed while resting on the subject's lap. In the second condition (EXT-TMS), the same procedure was used, except that occasionally (4 times per trial) TMS was applied. In the third one (EXT-TMS-GRIP), the procedure was similar to EXT-TMS, but the hand was no longer relaxed and the subject had to generate a constant GF of $3 \mathrm{~N}$. The underlying motivation was to assess whether activity in M1, independently of eye-hand coordination, could influence the effect of TMS on eye motion. In both TMS conditions, the order of trial playback was identical as in EXT. Finally, in a fourth condition (EXT-TACT), the experimenter moved the target by placing his hand over the participant's relaxed hand, which was holding the force sensor (Fig. $1 B$ ). The rationale was to assess the possible contribution of tactile information under SELF eye-tracking performance. This procedure did not allow us to present the same target trajectories as in the other EXTERNAL conditions, but we ensured comparable mean target velocities.

Overall, we explored a total of 8 experimental conditions. Each participant performed 1 block of 10 trials (30 s each) in each of these experimental conditions. The order of the blocks was randomized, except the SELF block, which had to be completed first before participants could perform the EXT, EXT-TMS, and EXT-TMS-GRIP blocks.

After the completion of these 8 blocks, half of the subjects completed an extra block of 10 trials. During this last block, the self-moved target was unexpectedly blanked 4 times per trial. In one-half of these blanks, TMS was triggered slightly after target extinction (SELF-TMS-BLANK). In the other half, blanks were not accompanied by TMS (SELF-BLANK). We reasoned that the removal of visual feedback would likely increase the saliency of hand efferent signals, and thus possibly augment the perturbing effect of TMS. 
Timeline of TMS and target occlusion. The initiation of TMS was fully determined by the ongoing kinematics of the target. We intended to trigger TMS around the center of oscillation (Gagnon et al., 2006; Nuding et al., 2009), namely, when absolute target velocity was high $(>40 \%$ s) and absolute acceleration was low $\left(<2 \% \mathrm{~s}^{2}\right)$. Within each trial, TMS was applied four times: twice during a rightward target motion and twice during a leftward target motion, with an order that was randomized across trials. We also imposed that TMS could not be triggered during the first $4 \mathrm{~s}$, and that consecutive TMS pulses were separated by at least $4.5 \mathrm{~s}$. During the SELF conditions, this experimental design implied that TMS could be triggered either during an increasing or a decreasing contraction of the fingers. In agreement with earlier observations (Cros et al., 2007; Gruet et al., 2013), we found that MEPs and GF pulses were substantially greater during an increasing contraction $(\mathrm{MEP}=3.78 \pm 1.82 \mathrm{mV}$; GF pulses $=1.68 \pm 0.49 \mathrm{~N})$ than a decreasing one $(\mathrm{MEP}=2.05 \pm 1.53 \mathrm{mV}$; GF pulses $=0.73 \pm 0.13 \mathrm{~N}$ ) (for more details, see Data analysis). The rationale to trigger TMS during increasing and decreasing contractions was to investigate whether the effect of TMS on eye motion would scale with MEP magnitude. However, as will be exposed later, TMS had no short-latency effect on SP during both increasing and decreasing contractions; we thus have decided to pool these two types of contraction in Results. Because a similar conclusion was obtained for TMS during rightward and leftward motion of the target during EXTERNAL trials, those observations were also pooled.

Regarding transient target occlusions during SELF-BLANK, the duration of occlusion ( $400 \mathrm{~ms}$ ) was chosen to be in the range of values used by others (Mehta and Schaal, 2002; Bennett and Barnes, 2003; Orban de Xivry et al., 2008; Landelle et al., 2016). The following constraints were used to trigger target occlusions. First, occlusions could only be initiated during rightward movement (increasing contraction), namely, when target velocity was close to $0(<0.1 \%$ s), and target acceleration was high $\left(>300 \% \mathrm{~s}^{2}\right)$. Second, we imposed that target occlusions could not be introduced during the first $4 \mathrm{~s}$, and that they had to be separated by at least $4.5 \mathrm{~s}$. Third, four occlusions were triggered per trial. In two of them, TMS was triggered $150 \mathrm{~ms}$ after the initiation of the blank. This procedure allowed to trigger TMS around the center of oscillation (as in SELFTMS). Before this block, participants were informed about the possible occurrence of TMS and target occlusions, but they were instructed to keep their eyes on the target as if it was still present on the screen.

Data analysis. Because the stimuli were moving exclusively along the horizontal meridian, we focused our analyses on the horizontal component of eye movements. We then performed a sequence of analyses to separate periods of SP, saccades and blinks from the raw eye position signals. The identification of the blinks was performed based on the pupil diameter (that was also recorded). This procedure led to the removal of $<1 \%$ of eye recordings. Eye position time series were then low-pass filtered with a Butterworth (fourth order) using a cutoff frequency of $25 \mathrm{~Hz}$. The resultant eye position signals were differentiated to obtain the velocity traces. The eye velocity signals were low-pass filtered with a cutoff frequency of $25 \mathrm{~Hz}$ to remove the noise from the numerical differentiation. The resultant eye velocity signals were then differentiated to provide the acceleration traces that we also low-pass filtered at $25 \mathrm{~Hz}$ to remove the noise. A dedicated MATLAB script was used to identify the beginning and end of each saccade. This identification was based on the acceleration and deceleration peaks of the eye $\left(>1500^{\circ} / \mathrm{s}^{2}\right)$. Further visual inspection allowed to identify smaller saccades $\left(<1^{\circ}\right)$ that could not be identified automatically by our program. Based on these computations, epochs of pursuit and of saccades were extracted.

To assess the participants' ability to predict the dynamics of the target or hand-target during visually guided tracking, we computed several dependent variables. First, we computed the mean absolute position error (PE) by averaging the absolute difference in position between the target and the eye over the whole trial. Second, we computed the mean absolute velocity error (VE; i.e., the average absolute difference between the eye and target velocity). Although PE was evaluated over the whole trial (i.e., including both periods of saccades and SP), VE was computed only during SP periods. Third, to evaluate the temporal relationship between the eye and target movements, we computed the lag between eye and target velocity signals using a cross-correlation (a positive lag corre- sponding to the eye lagging behind the target). This lag computation was based on the eye signal excluding saccades. Finally, we computed the SP gain by averaging the ratio between instantaneous eye and target velocities during phases of SP (to avoid numerical instabilities, only situations where absolute target velocity was $>10^{\circ} / \mathrm{s}$ were considered). For all these analyses, the first second of each trial was discarded.

Regarding the effect of TMS, we tried first to characterize its effect on hand action. The latency and magnitude of changes in GF and MEP in first dorsal interosseous were computed. The latency of MEP was calculated with the following procedure. Mean and SD of rectified EMG was determined in the $100 \mathrm{~ms}$ window preceding TMS. Then in the subsequent data points, we identified the moment at which EMG went above a threshold value that was set to mean EMG + 2 SD (Danion et al., 2003; Volz et al., 2015). A similar procedure was adopted to determine the latency of GF pulses induced by TMS. To assess the magnitude of TMSinduced changes, we measured the peak-to-peak amplitude of MEP and GF pulses within the next $100 \mathrm{~ms}$ that followed the individual latencies.

Concerning the effect of TMS on SP, another set of analyses was conducted to investigate possible alteration in SP velocity after TMS (up to $150 \mathrm{~ms}$ ). To achieve this goal, we used a linear interpolation routine to bridge the gaps produced by removal of saccades from the eye velocity trajectory (Bennett and Barnes, 2003). Possible alterations in SP velocity were investigated both at the level of its mean value and its fluctuation across trials. To address this issue, for each subject, and in each condition, we computed the mean and standard error (SE) of SP velocity across trials for each of the 150 time points following TMS. As TMS was triggered based on target velocity, we did not explicitly control SP velocity at that moment, and observed some disparities across experimental conditions with group mean velocities ranging from 13.3 to $18.6 \%$. We also noticed that, in some cases, eye velocity could be really low $(<5 \%$ ), plus blinks could also occur in the vicinity of TMS. Because the effect of TMS has been shown to depend substantially on SP velocity (Gagnon et al., 2006; Nuding et al., 2009), we felt it was critical to exclude the earlier cases and equalize SP velocity at the moment of TMS. This was achieved by selecting observations in which velocity was closest from $20 \%$, an eye velocity previously studied and reported sensitive to TMS over frontal eye field (Gagnon et al., 2006). Overall, for each condition and each participant, we kept 20 observations ( 10 rightward +10 leftward) out of the 40 available.

Statistical analysis. We decided not to use a statistical design that included all the experimental conditions. Instead, our statistical analyses were designed to address some specific issues. The first one was to confirm that eye tracking was more accurate when subjects moved the target themselves compared with when it was moved by an external agent. To address this point, we focused on the comparison between eye tracking performance in SELF, EXT, and EXT-TACT. Specifically, we compared PE, VE, eye-target lag, and SP gain over whole trials. A second issue was to assess the possible effect of TMS in the absence of eye-hand coordination (externally moved target). To achieve this goal, we focused on SP eye movements in EXT, EXT-TMS, and EXT-TMS-GRIP. Specifically, we looked for possible differences in terms of PE and VE over the $200 \mathrm{~ms}$ that followed TMS. To investigate possibly more subtle effects of TMS, we also inspected SP velocity profiles associated with each of the three external conditions, along with statistical analyses of mean SP velocity within the 25-125 ms epoch following TMS (Gagnon et al., 2006). Data alignment was based on target trajectory, which was similar in all these three conditions. Subsequently, we assessed the possible effect of TMS during eye-hand coordination (self-moved target). This time, we focused on the comparison between SELF, SELF-TMS, SELF-MIMIC, and SELF-TMS-MASK. To separate the possible contribution of TMS and the occurrence of a target jump, two-way repeated-measures ANOVA was performed with TMS (with/without) and T-JUMP (with/ without) as within-subject factors. Again, we searched for possible differences in terms of PE, VE, and SP velocity immediately after TMS. Segments of eye motion in SELF in which target trajectory fulfilled our criteria for the initiation of TMS were used for baseline performance. Finally, we assessed the possible effect of TMS during eye-hand coordination in the absence of visual information by using data collected 
in SELF-BLANK and SELF-TMS-BLANK. Here, the comparison was based on velocity profiles obtained in the presence/absence of TMS during target occlusion, along with comparable data from the SELF condition.

For all these issues, we used repeatedmeasure ANOVA to assess the effect of experimental conditions. Tukey corrections were used for post hoc $t$ tests to correct for multiple comparisons. A conventional 0.05 significance threshold was used for all analyses.

\section{Results}

Eye tracking performance during selfmoved versus externally moved target Figure 3 shows mean group eye movements' variable in conditions SELF, EXT, and EXT-TACT. As largely expected, eyetracking performance was substantially improved when the target was self-moved compared with when it was externally moved. This conclusion is valid for all the dependent variables. Regarding PE (Fig. $3 A$ ), one-way ANOVA revealed a main effect between these experimental conditions $\left(F_{(2,22)}=70.66 ; p<0.001\right)$. Post hoc tests showed that PE in SELF was significantly smaller than in EXT and EXTTACT $(p<0.001)$, increasing PE by $44 \%$ and $61 \%$, respectively. A significant difference was also found between the two external conditions such that PE was slightly greater in EXT-TACT compared with $\operatorname{EXT}(p<0.05)$, suggesting that the provision of tactile information was not helpful. Rather similar conclusions were drawn from the analysis of VE (Fig. 3B). Indeed, the ANOVA showed a main effect of conditions $\left(F_{(2,22)}=40.94 ; p<0.001\right)$, with post hoc tests indicating that VE during SELF was significantly lower compared with EXT and EXT-TACT $(p<$ 0.001 ), both latter indices being not significantly different from each other $(p>$ 0.05).

Regarding the temporal relationship between eye and target (Fig. 3C), the eye was always lagging behind the target, albeit with different delays depending on the experimental conditions as revealed by a main effect $\left(F_{(2,22)}=42.85 ; p<\right.$ 0.001). Post hoc tests confirmed that the eye was lagging significantly less $(p<0.001)$ on the target during SELF (mean lag $=53 \mathrm{~ms}$ ) compared with EXT (mean lag $=84$ $\mathrm{ms}$ ) and EXT-TACT (mean lag $=92 \mathrm{~ms}$ ). Overall, the benefit provided by self-moving the target was on the order of $30-40 \mathrm{~ms}$. Again, we found no significant difference between EXT and EXTTACT $(p>0.05)$. Results provided by the analyses of the SP gain led to almost identical conclusions (Fig. 3D). ANOVA showed a significant difference across conditions $\left(F_{(2,22)}=13.91 ; p<\right.$ 0.001 ), with post hoc tests indicating higher SP gain in SELF compared with EXT and EXT-TACT $(p<0.05)$. Finally, we observed a slightly lower SP gain in EXT-TACT compared with EXT $(p<$ $0.05)$. accurate during SELF.

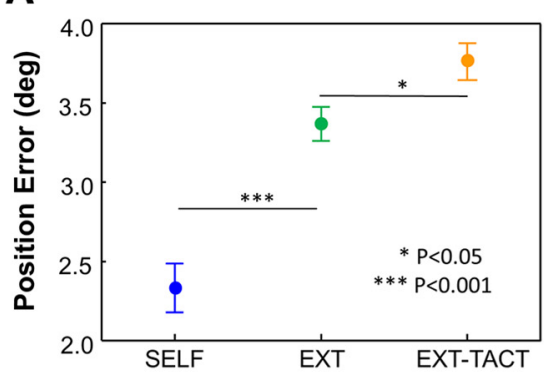

B
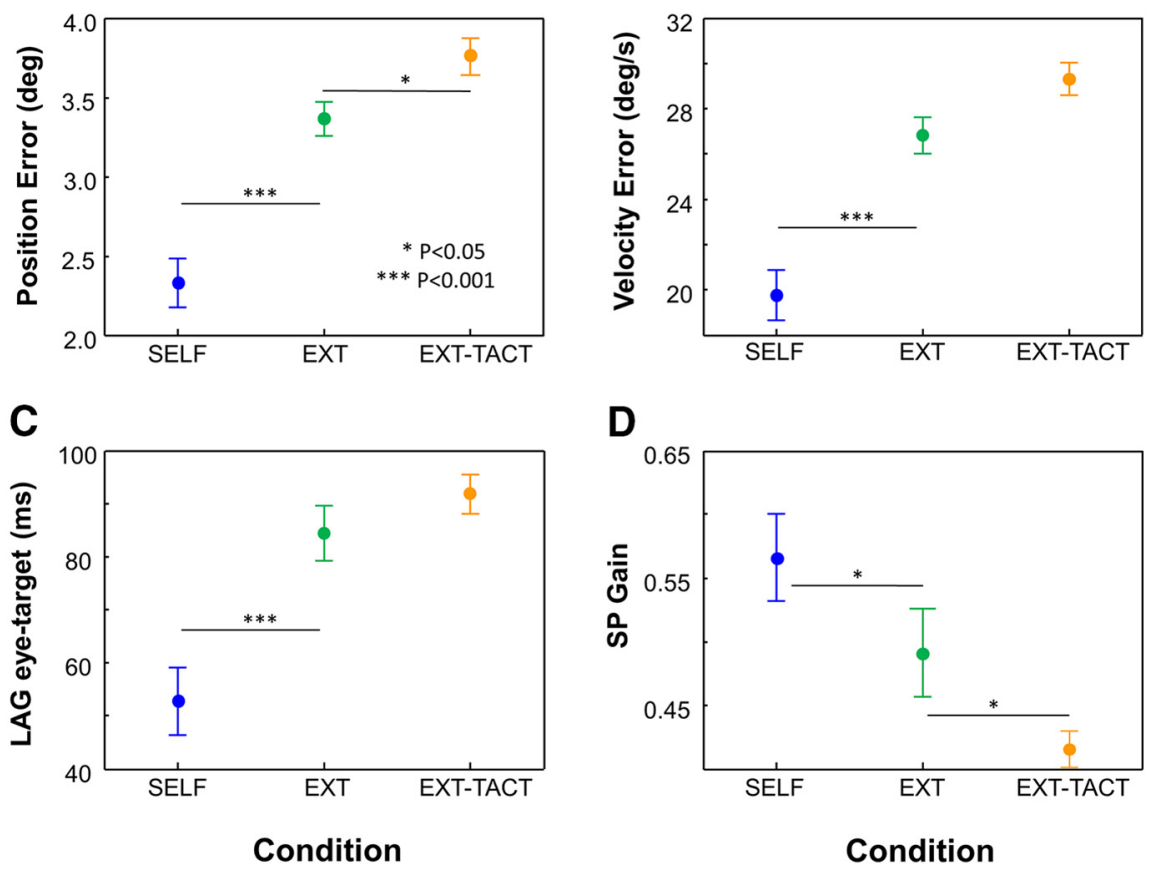

Figure 3. Mean group eye-tracking performance during SELF, EXT, and EXT-TACT. PE $(\boldsymbol{A}), \operatorname{VE}(\boldsymbol{B})$, eye-target lag ( $(\boldsymbol{C}$, and SP gain (D). Measurements are performed over the whole trial. Error bars indicate SEs. For all indices, eye tracking performance was more

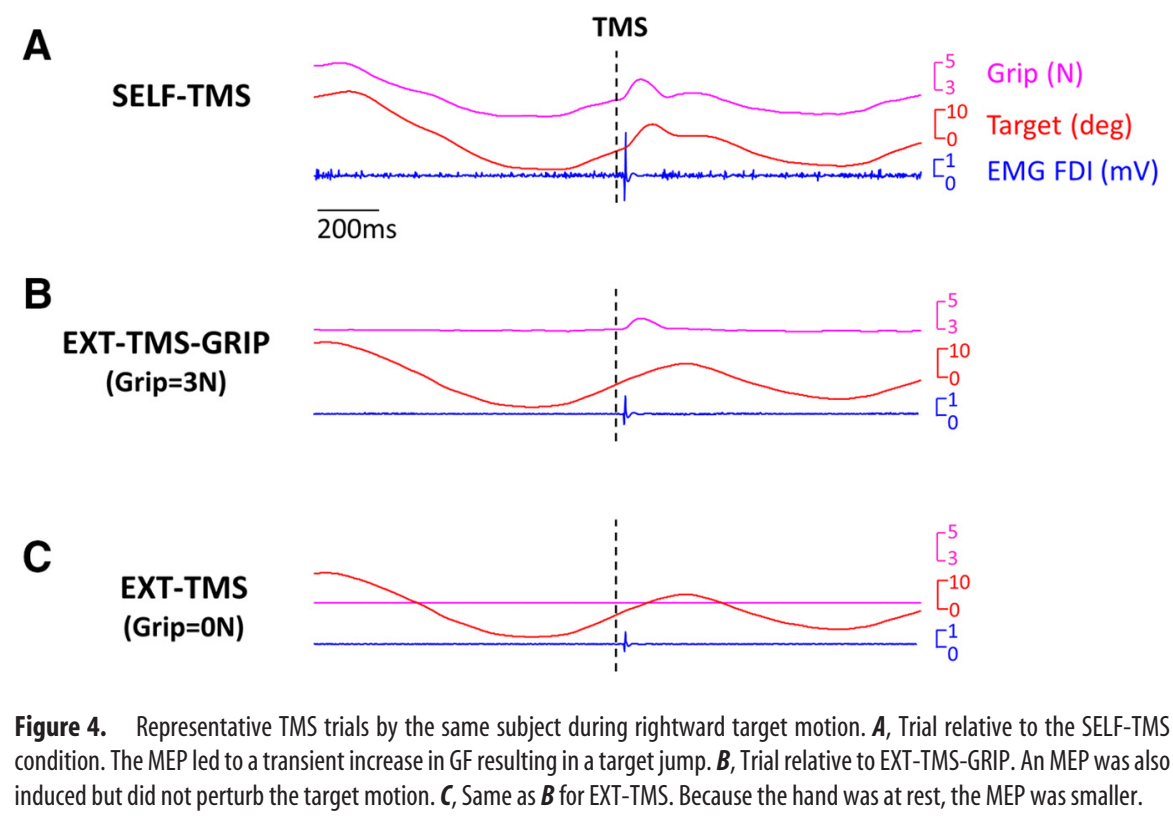

Focusing on the post hoc analyses between EXT and EXTTACT, it seems that tactile feedback could actually impair eyetracking performance in terms of PE and SP gain. Because target trajectories were not the same in these two conditions, we examined their degree of randomness by means of approximate entropy, also known as ApEn (Pincus, 1991; see also Landelle et al., 2016). These analyses showed that target trajectories in EXTTACT were indeed slightly more complex than in EXT (7\% difference in ApEn). Further analyses in which ApEn was equalized across the two conditions showed that differences in SP gain were no longer significant (while remaining significant for PE). 

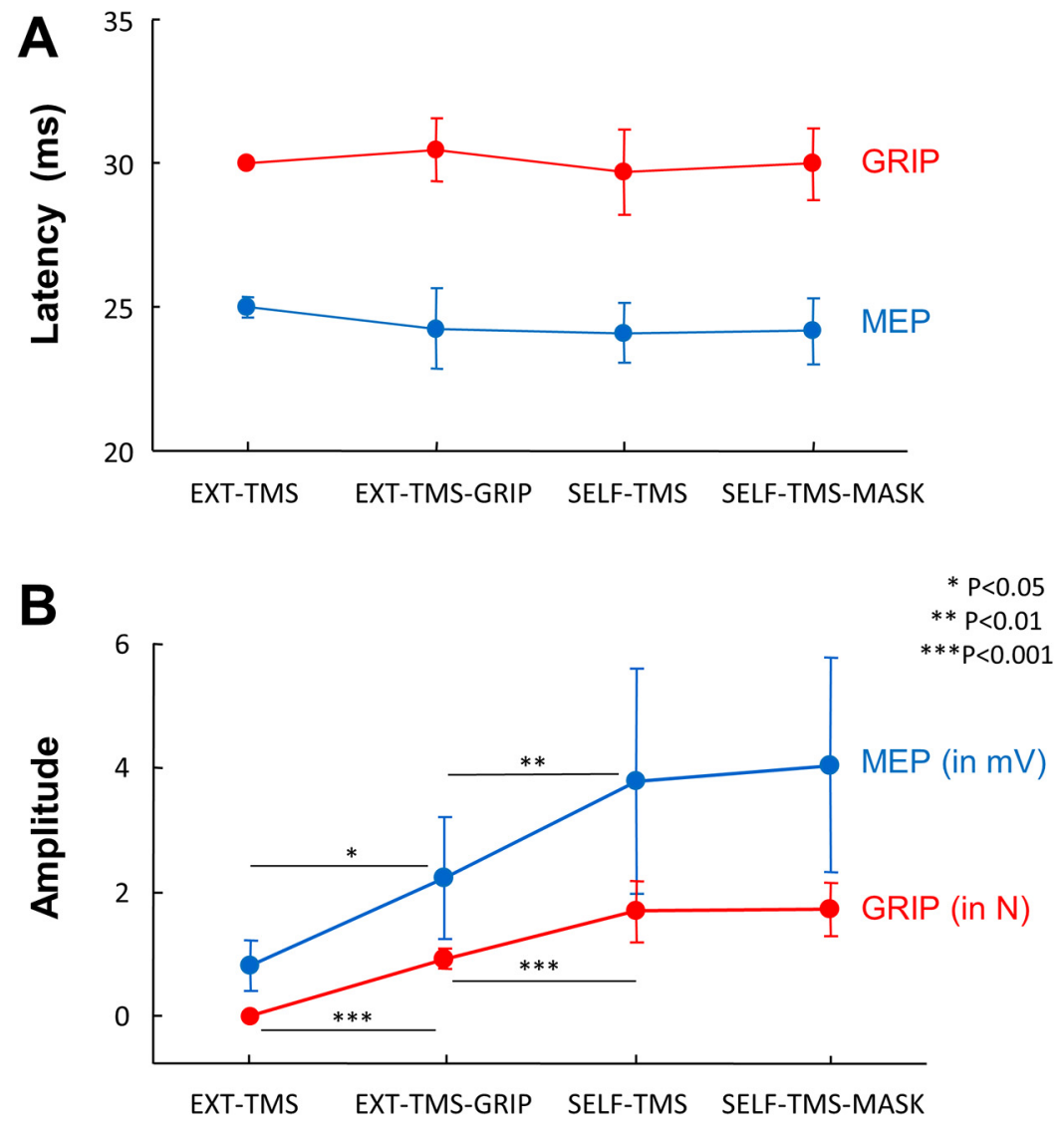

Condition

Figure 5. Effect of TMS on hand action as a function of experimental condition during rightward target motion. $A$, Mean group latency of MEP and GF pulse. $\boldsymbol{B}$, Mean group magnitude of MEP and GF pulse. Error bars indicate SEs.
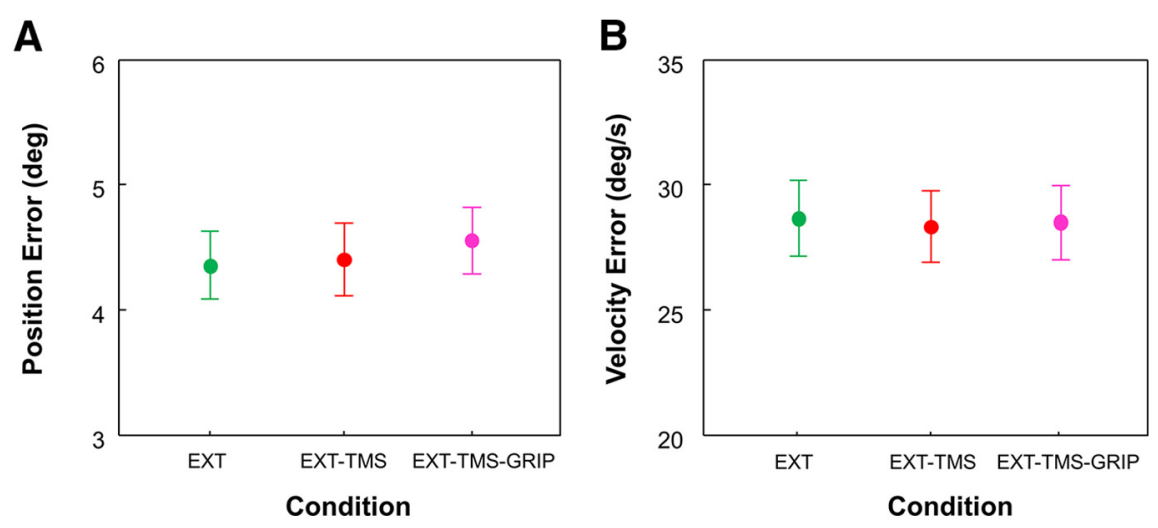

Figure 6. Effect of TMS on eye tracking performance during EXTERNAL conditions. $A$, Mean group PE within the next 200 ms that followed TMS or equivalent period in the no TMS condition. Error bars indicate SEs. $\boldsymbol{B}$, Same as $\boldsymbol{A}$ for VE.

\section{Effects of TMS on hand action}

Before we present the effects of TMS on eye motion, we propose to quickly address the effect of TMS on EMG and GF. Figure 4 presents one typical trial during rightward target motion by the same subject in each of the following conditions: SELF-TMS, EXT-TMS-GRIP, and EXT-TMS. In each of these trials, TMS over M1 was immediately followed by an MEP in the first dorsal interosseous muscle, and by a transient increase in GF when the hand was already active. In Figure 5, we present mean group data regarding the latency and amplitude of those MEPs and GF pulses as a function of experimental condition during rightward target motion. As exposed on Figure $5 A$, averaged across conditions, the mean latency of MEP and GF changes was $24.4 \pm 0.4$ and $30.0 \pm 0.4 \mathrm{~ms}$ (SD across conditions), respectively. Similar latencies were observed during leftward target motion. Those values are in the vicinity of values reported in other studies that investigated the effect of TMS over M1 during isometric contraction of hand muscles (Danion et al., 2003; Cros et al., 2007). Additionally, the fact that MEPs preceded slightly GF changes is in line with our previous report (Danion et al., 2003) as well as with the existence of an electromechanical delay between EMG and force. Regarding the magnitude of MEPs and GF pulses (Fig. 5B), it changed depending on the experimental condition. As expected, we found that MEPs were substantially greater with prior GF exertion compared with when the hand was relaxed $(p<0.05)$. Furthermore, MEPs (and GF pulses) were greater during increasing contractions (SELF-TMS and SELF-TMS-MASK) compared with steady ones (EXT-TMS-GRIP; $p<0.01$ ). Although the magnitude of MEPs and GF pulses in EXTERNAL conditions did not change with target motion direction $\left(F_{(1,11)}<1.33 ; p>0.27\right)$, the effect of TMS during SELF conditions was boosted by increasing contractions $\left(F_{(1,11)}>\right.$ 22.17; $p<0.001$ ), both indices being approximately doubled. Finally, the magnitude of GF pulses and MEPs were strongly correlated across experimental conditions $(r=0.995, p<0.01)$. Further analyses showed that this correlation also held when focusing on individual data collected during SELF-TMS (mean group, $R>0.62, p<0.001$ ), suggesting that target deflections induced by TMS reflected rather well the magnitude of the corticospinal volley.

\section{Effect of TMS on eye tracking performance}

Tracking a target moved by an external agent

Figure 6 compares eye-tracking performance within the next $200 \mathrm{~ms}$ that followed TMS in EXT-TMS and EXT-TMSGRIP with eye-tracking performance during comparable time periods in EXT. As illustrated by this figure, TMS did not seem to interfere with eye tracking. Indeed, ANOVA showed no significant difference across conditions for both $\operatorname{PE}\left(F_{(2,22)}=1.68 ; p=\right.$ 0.21 ; Fig. $6 A)$ and $\operatorname{VE}\left(F_{(2,22)}=0.12 ; p=0.89\right.$; Fig. $\left.6 B\right)$.

In Figure $7 A$, we present the mean SP velocity profiles associated with each of the three external conditions. As reflected by largely overlapping profiles, TMS did not seem to impact on SP velocity. One-way ANOVA failed to show a significant difference 
across conditions in terms of mean SP velocity within the 25-125 ms epoch $\left(F_{(2,22)}=1.29 ; p=0.29\right)$. However, because TMS could simply alter the stability of SP velocity (by sometimes accelerating, or decelerating, eye motion), we also inspected the associated variability of SP velocity across trials. As illustrated in Figure $7 B$, this variability was comparable across conditions. ANOVA conducted for the 25-125 ms epoch showed no significant difference across conditions $\left(F_{(2,22)}=\right.$ $0.03 ; p=0.96)$. Overall, these analyses demonstrate that, when subjects track with their eyes an externally moved target, TMS over M1 has no obvious impact on eye tracking performance and SP.

Tracking a self-moved target

Figure $8 A, B$ compares eye-tracking performance within the next $200 \mathrm{~ms}$ that followed TMS in SELF-TMS and SELFTMS-MASK with eye-tracking performance during comparable time periods in SELF-MIMIC and SELF. Results showed that the accuracy of eye tracking performance was altered by the target jump, but it was not influenced by TMS. Indeed, we observed a main effect of T-JUMP leading to an increase of PE $\left(F_{(1,11)}=20.29 ; p<\right.$ $0.001)$ and $\operatorname{VE}\left(F_{(1,11)}=275.14 ; p<\right.$ $0.001)$ following a target jump. In contrast, for both indices, we found no main effect of $\operatorname{TMS}\left(F_{(1,11)}<2.03 ; p>0.18\right)$ or interaction between TMS and T-JUMP $\left(F_{(1,11)}<0.89\right.$; $p>0.36$ ),

Again, to investigate possibly more subtle effects of TMS, further analyses were performed on SP velocity and its stability. In Figure 9A, we present the mean $S P$ velocity profiles associated with each of the four SELF conditions. As illustrated by the histogram two-way ANOVA during the 25-125 ms time interval showed no main effect of TMS $\left(F_{(1,11)}=2.07 ; p=0.17\right)$ or main effect of T-JUMP $\left(F_{(1,11)}=0.11\right.$; $p=0.74)$. Furthermore, SP velocity did not become more variable across trials following TMS (Fig. 9B). As illustrated by the histogram, ANOVA showed no significant main effect of TMS and T-JUMP $\left(F_{(1,11)}<0.79 ; p>0.39\right)$. Overall, these analyses demonstrate that, although TMS has a detrimental impact on eye tracking performance, this effect simply follows from the target jump associated with TMS. More importantly, these results show that, even during eye-hand coordination, TMS over M1 does not impact on SP.

\section{Tracking an invisible self-moved target}

Figure 10 presents the profiles of mean absolute SP velocity in the presence and absence of target occlusions (tested only for 6 subjects) while separating occluded trials with and without TMS. This figure shows that absolute SP velocity started to decrease $\sim 200$ ms after target masking, a phenomenon reported previously (Landelle et al., 2016). One-way ANOVA revealed no significant difference across these three types of trials within the
B

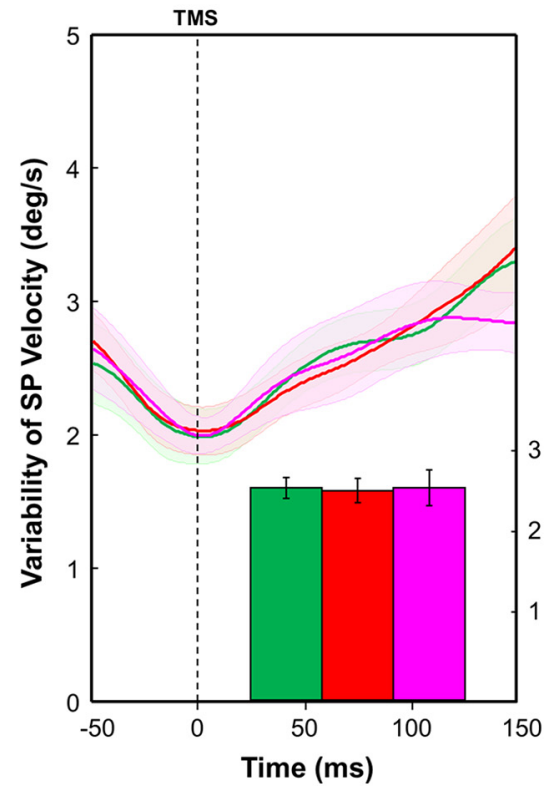

Figure 7. Effect of TMS on SP during EXTERNAL conditions. $A$, Mean group SP velocity profile within the 150 ms that followed following TMS. Error bars and shaded area around each trajectory represent SEs. $\boldsymbol{B}$, Same as $\boldsymbol{A}$ for variability of SP velocity across

A

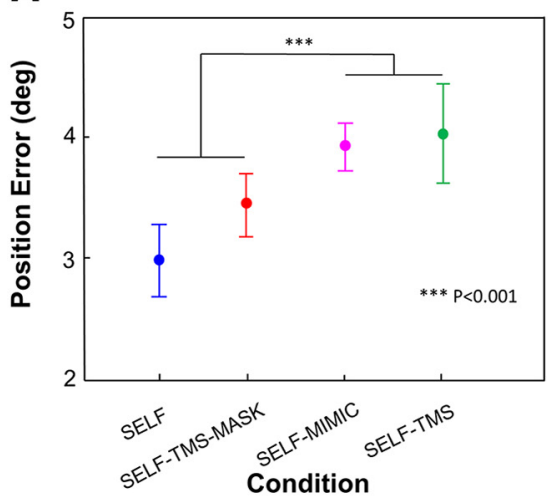

B

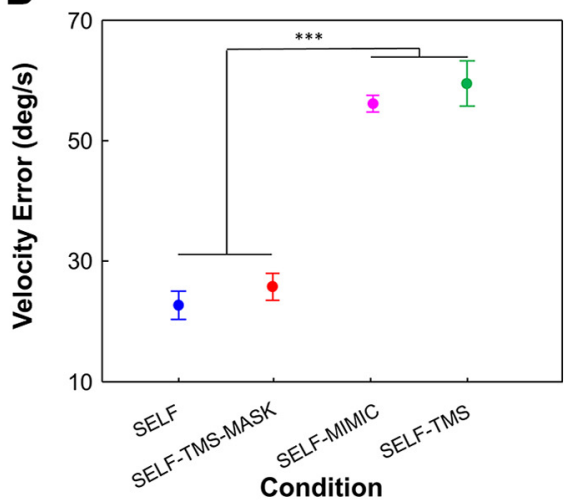

Figure 8. Effect of TMS on eye tracking performance during SELF conditions. $\boldsymbol{A}$, Mean group PE within the next 200 ms that followed or could have followed the target perturbation. Error bars indicate SEs $\boldsymbol{B}$, Same as $\boldsymbol{A}$ for VE.

25-125 ms epoch following target occlusion $\left(F_{(2,10)}=2.42 ; p>\right.$ $0.14)$. However, within the $175-275 \mathrm{~ms}$ epoch following target occlusion (i.e., 25-125 ms epoch following TMS), a main effect across conditions was observed $\left(F_{(2,10)}=8.42 ; p<0.01\right)$. Post hoc tests indicated that SP velocity in occluded trials was substantially reduced compared with nonoccluded trials $(-38 \% ; p<0.01)$. With respect to the effect of TMS, post hoc tests failed to show any significant difference between occluded trials with and without TMS $(p>0.90)$. Together, we conclude that, even when visual information about the target is lacking, TMS over M1 has limited contribution to eye-hand coordination as observed through SP velocity profiles.

\section{Control experiment}

At this stage, TMS over M1 had virtually no effect on SP velocity. However, our study may suffer from two limitations. First, although TMS intensity was set at $110 \%$ of AMT ( $~ 100 \%$ of resting motor threshold) and evoked reliable MEPs in all our conditions, 
A

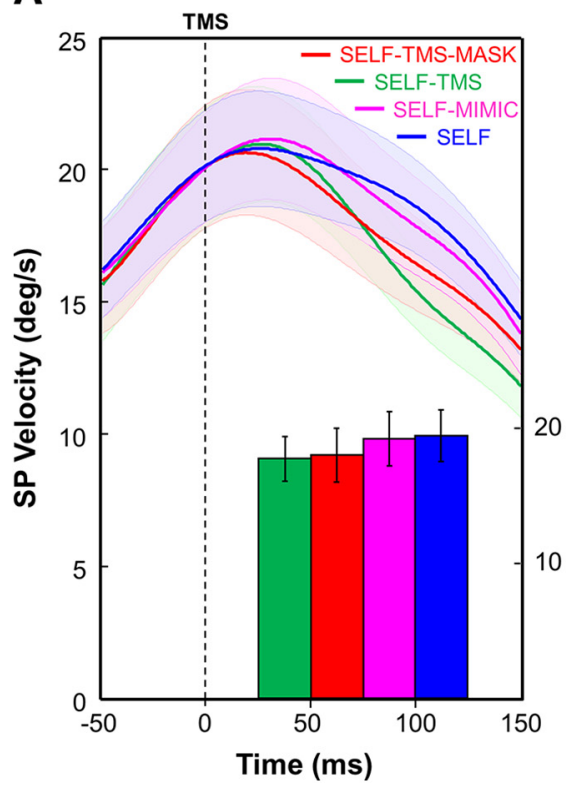

B

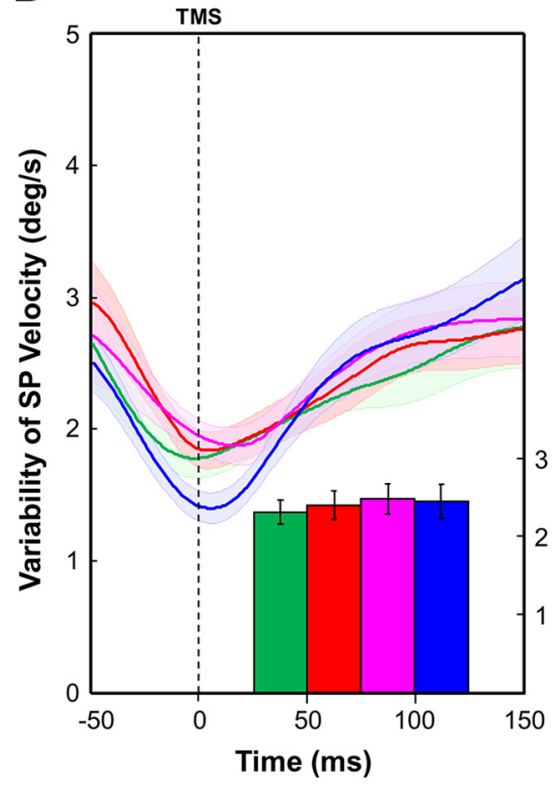

Figure 9. Effect of TMS on SP during SELF conditions. A, Mean group SP velocity profile within the $150 \mathrm{~ms}$ that followed TMS. Vertical dotted line indicates the timeline of TMS. Histogram represents mean group SP velocity within the 25-125 ms epoch following TMS. Error bars and shaded area around each trajectory represent SES. $\boldsymbol{B}$, Same as $\boldsymbol{A}$ for variability of SP velocity across trials. TMS did not impact on SP velocity and its stability.

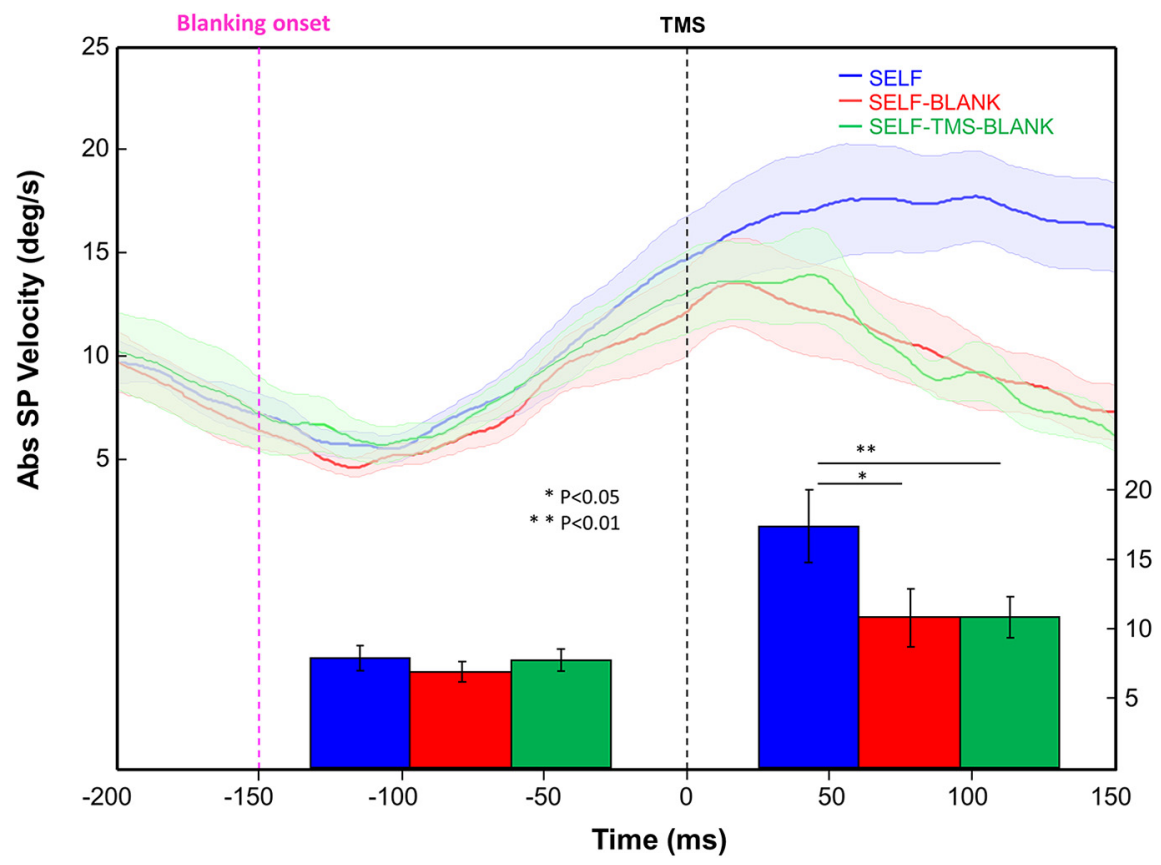

Figure 10. Effect of TMS and target occlusion on mean absolute SP velocity as a function of experimental condition. Black vertical dotted line indicates the timeline of TMS. Pink vertical line indicates the onset of the blanking period. Error bars and shaded area around each trajectory represent SEs. Histograms represent the mean absolute SP velocity during the $25-125 \mathrm{~ms}$ epoch before and after TMS. In contrast to TMS, masking the target altered SP velocity (by up to 50\%).

this intensity might seem low considering that effects on SP over other brain regions have been reported using higher intensities ranging from 110\% (Gagnon et al., 2006; Drew and van Donkelaar, 2007) to $130 \%$ resting motor threshold (Coubard and Kapoula, 2006). Second, one may also argue that our procedure for equalizing SP velocity across conditions resulted in discarding half of the trials, and lower statistical power might lead to the emergence of a null finding. To address these two potential con- founds, we have run a control experiment with 6 healthy right-handed volunteers (age: $27.3 \pm 10.0$ years, 5 male). This time TMS intensity was set at $130 \%$ AMT (52.8 $\pm 6.7 \%$ of maximum stimulator output), which basically doubled the magnitude of GF pulses induced by TMS $(+2.2 \mathrm{~N})$. In addition, TMS was no longer triggered by current target velocity but by current eye velocity, which had to be in the vicinity of $20 \%$ (range: $17-23 \%$ s), making the homogenization of SP velocity unnecessary. Finally, the number of trials per condition was increased from 10 to 15 , leading potentially to 30 rightward and 30 leftward observations. Each participant completed one block of 15 trials in each of the following conditions: EXT-GRIP, EXT-TMS-GRIP, SELF, and SELF-TMS. All the other aspects of the protocol were similar to the main experiment. Despite the fact that blinks became more frequent at this TMS intensity (see also Xu-Wilson et al., 2011), we managed to keep an average of $53.6 \pm 3.8$ observations per participant (range: 40-60), which nearly tripled the number observations collected in the main experiment.

The corresponding mean group SP velocity profiles in the EXTERNAL and SELF conditions are presented in Figure $11 A$ and Figure $11 B$, respectively. As in the main experiment, no obvious changes were found following TMS. Indeed, oneway ANOVA on mean SP velocity during the 25-125 ms epoch showed no main effect of TMS during both EXTERNAL and SELF conditions $\left(F_{(1,5)}<0.78 ; p>0.41\right)$. Further analyses of SP variability during SELF also showed no main effect of TMS $\left(F_{(1,5)}=0.55 ; p=0.48\right)$. In Figure 11, $C$ and $D$, we present the resulting SP velocity profile for 2 participants in the SELF conditions, supporting the lack of TMS effect. Overall, increasing both TMS intensity and the number of observations did not change our main conclusion.

\section{Discussion}

Our main objective was to investigate the possible contribution of M1 hand area in eye motion during eye-hand coordination. To address this issue, we investigated the effect of single-pulse TMS when tracking with the eyes a visual target that was either self-moved by the hand or moved by an external agent. At this stage, our study brought the following key observations. First, despite the fact that the target was moved by means of GF, our results add further evidence that eye-tracking is more accurate when the target is self-moved. Second, when tracking an externally moved target, the provision of tactile feedback did not benefit to eye tracking, thereby comforting the key role of hand efferent signals. Third, TMS did not 
interfere with eye-tracking performance when dealing with an externally moved target. Fourth, TMS altered eye-tracking performance of a self-moved target, but a similar effect was observed with a visual perturbation that mimicked the effect of TMS on the target. In addition, eye tracking performance was not altered by TMS when its visual consequences on the target were masked. Fifth, even during eye-hand coordination tasks, SP remained largely insensitive to the application of TMS, no matter whether the self-moved target was occluded or not. Finally, increasing TMS intensity and the number of observations per participant did not change our main finding (i.e., TMS over M1 has virtually no effect on SP). We plan now to discuss in more details those findings and their implications.

\section{Self-moved versus externally moved target}

As in many earlier studies (Steinbach and Held, 1968; Vercher et al., 1995; Chen et al., 2016), the current study demonstrates that eye tracking is more accurate under SELF than EXTERNAL. However, it is worth emphasizing that, in contrast to these previous studies in which target motion was directly driven by the motion of the hand, here the hand was immobile and the target was driven by means of GF modulation. Despite that moving the target in this way may feel less intuitive or conventional, comparisons between the current dataset and our earlier one (Landelle et al., 2016) show rather similar eye-tracking performance as reflected by PE (here 2.3 vs $1.9^{\circ}$ ), VE ( 20 vs $19^{\circ} / \mathrm{s}$ ), eye-target lag ( 53 vs 30 $\mathrm{ms})$, and SP gain (0.57 vs 0.48). Overall, this comparison demonstrates the stunning flexibility of the predictive mechanisms involved in eye-hand coordination with regard to the motor signals underlying the target motion.

Another contribution of our study is to show that tactile feedback is poorly relevant for the tracking of an externally moved target. This lack of benefit provided by tactile feedback is consistent with earlier observations made by Vercher et al. (1996), who also found little improvement in SP initiation when providing proprioceptive feedback by means of passive arm movements. The fact that eye tracking an externally moved target does not improve much with the provision of tactile or proprioceptive feedback is congruent with the fact that hand motor signals are crucial for accurate eye-hand coordination. How hand motor signals might contribute to eye motion will be discussed in the next section.

\section{Limited effect of TMS on SP}

Earlier studies have shown that, when TMS is applied over oculomotor or visual areas (such as frontal eye field, MT, or cerebellum) while tracking an externally moved target, SP can be speeded up or slowed down (Ohtsuka and Enoki, 1998; Gagnon et al., 2006; Nuding et al., 2009; Haarmeier and Kammer, 2010). Here by applying TMS over the M1 hand area, even at high intensity (130\% AMT), we found no consistent changes in SP velocity nor signs that its stability was altered. Importantly, this
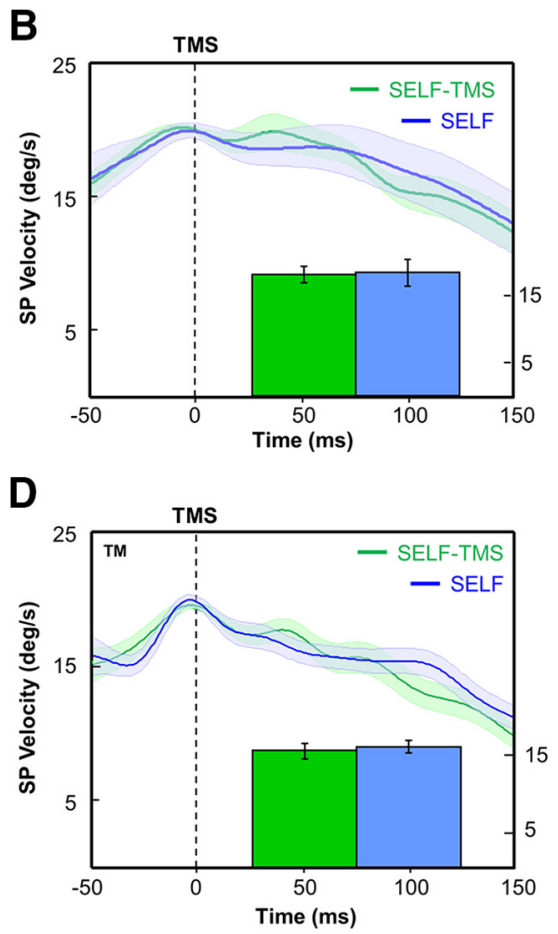

Figure 11. Effect of TMS on SP during the control experiment. $\boldsymbol{A}$, Mean group SP velocity profile during the EXTERNAL condifllowing TMS. Error bars and shaded area around each trajectory represent SEs. B, Same as $\boldsymbol{A}$ for the SELF conditions. C, D, Same as $\boldsymbol{B}$ for two representative participants. Error bars and shaded area represent SE across trials. In all cases, TMS did not impact on SP finding was obtained for tasks that did not involve the hand, but also for tasks that required accurate eye-hand coordination (Figs. 7, 9-11). Overall, it appears that background neural activity in M1 was not critical because we consistently observed that SP was insensitive to TMS no matter the hand was at rest (EXTTMS), maintaining a constant GF (EXT-TMS-GRIP), or modulating GF (SELF-TMS). We conclude that SP is driven by neural processes sufficiently robust to endure the corticospinal volley evoked by TMS over M1. Although this conclusion fits rather well with other studies showing a lack of effect when TMS was applied over nonvisual or nonoculomotor areas, such as the vertex (Drew and van Donkelaar, 2007; Nuding et al., 2009) or the leg somatosensory area (Gagnon et al., 2006), it is noteworthy to mention that all these studies relied on the visual tracking of an externally moved target and therefore did not involve any eye-hand coordination. In the next paragraphs, we focus more on the lack of effect of TMS during eye-hand coordination.

At this stage, we are not aware of any other study that has investigated the effect of TMS over M1 during SP, especially in the context of eye-hand coordination task. We found that the accuracy of eye-tracking performance decreased following TMS because the eye was unable to keep track of the target when it unexpectedly jumped. However, it is crucial to note that (1) a similar drop in performance was observed when we mimicked this target jump in the absence of TMS (SELF-MIMIC), and (2) conversely, no drop in performance was observed when the visual consequences of TMS were masked (SELF-TMS-MASK). Overall, these results show that, even though eye tracking performance was altered by TMS, this effect simply follows from the associated visual perturbation, but not from TMS per se. This view is congruent with our other analyses showing that SP velocity was not altered by TMS. Indeed, even when target visual feed- 
back was suppressed so as to encourage the use of hand efference signals, SP remained largely insensitive to TMS over M1. Overall, despite previous reports showing intricate relationship between hand and eye motor systems (Maioli et al., 2007; Elsner et al., 2013; Chen et al., 2016), the present study failed to show a causal relationship between activity in M1 and SP during eye-hand coordination.

\section{Neural substrate of eye-hand coordination}

The main objective of this experiment was to investigate the possible contribution of hand motor signals to the oculomotor system via M1. What should we conclude from the fact that, despite our multiple attempts, TMS over M1 never interfered with SP? A first possibility is to consider that we found no effect because the contribution of hand motor signals to the oculomotor system is performed upstream of M1. An alternative possibility is that hand motor signals do not contribute to eye-hand coordination because it is achieved through a common controller driving both effectors (van Donkelaar et al., 1994; Engel et al., 2000; Maioli et al., 2007). No matter which alternative is correct, our results indicate that eye-hand coordination is performed essentially upstream of M1. Neural structures, such as the posterior parietal cortex (Battaglia-Mayer et al., 2006; Dean et al., 2012), parietal reach region (Hwang et al., 2014), and dorsal premotor area (Passarelli et al., 2011), have been listed for their contribution in eye-hand coordination. However, we would like to stress that, in contrast to our study, these contributions were obtained in the context of tasks investigating the coordination between saccades and reaching movements. Importantly, during these tasks, there was no explicit requirement to follow the hand with the eyes. Finally, although our isometric task offers some key advantages for a well-controlled TMS experiment and has already been proven a useful tool (Sailer et al., 2005; Huang and Hwang, 2012), eye-hand coordination may rely on partly distinct processes during actual hand movements. Overall, future studies are encouraged to assess whether similar neural structures are involved in coordinating SP and saccades with ongoing arm actions, including hand movements and isometric contractions.

\section{General comments on efference copy}

The notion of efference copy is central in neuroscience. Not only does it account for perceptive (sensory cancellation) and cognitive processes (self-awareness), but it also accounts for many motor processes, in particular the coordination between multiple effectors (Kawato, 1999; Diedrichsen et al., 2010; Wolpert and Flanagan, 2010). In the context of sensory cancellation, previous TMS experiments (excepted Voss et al., 2007) have failed to show a contribution of M1 into the generation of hand efference copy (Chronicle and Glover, 2003; Voss et al., 2006; Timm et al., 2014). The current TMS study extends this scheme in the context of eye-hand coordination.

\section{References}

Angel RW, Garland H (1972) Transfer of information from manual to oculomotor control system. J Exp Psychol 96:92-96. CrossRef Medline

Ariff G, Donchin O, Nanayakkara T, Shadmehr R (2002) A real-time state predictor in motor control: study of saccadic eye movements during unseen reaching movements. J Neurosci 22:7721-7729. Medline

Battaglia-Mayer A, Archambault PS, Caminiti R (2006) The cortical network for eye-hand coordination and its relevance to understanding motor disorders of parietal patients. Neuropsychologia 44:2607-2620. CrossRef Medline

Bennett SJ, Barnes GR (2003) Human ocular pursuit during the transient disappearance of a visual target. J Neurophysiol 90:2504-2520. CrossRef Medline

Brasil-Neto JP, Cohen LG, Panizza M, Nilsson J, Roth BJ, Hallett M (1992) Optimal focal transcranial magnetic activation of the human motor cortex: effects of coil orientation, shape of the induced current pulse, and stimulus intensity. J Clin Neurophysiol 9:132-136. CrossRef Medline

Chen J, Valsecchi M, Gegenfurtner KR (2016) LRP predicts smooth pursuit eye movement onset during the ocular tracking of self-generated movements. J Neurophysiol 116:18-29. CrossRef Medline

Chronicle EP, Glover J (2003) A ticklish question: does magnetic stimulation of the primary motor cortex give rise to an "efference copy?" Cortex 39:105-110. CrossRef

Coles MG (1989) Modern mind-brain reading: psychophysiology, physiology, and cognition. Psychophysiology 26:251-269. CrossRef Medline

Coubard OA, Kapoula Z (2006) Dorsolateral prefrontal cortex prevents short-latency saccade and vergence: a TMS study. Cereb Cortex 16:425436. CrossRef Medline

Crawford JD, Medendorp WP, Marotta JJ (2004) Spatial transformations for eye-hand coordination. J Neurophysiol 92:10-19. CrossRef Medline

Cros D, Soto O, Chiappa KH (2007) Transcranial magnetic stimulation during voluntary action: directional facilitation of outputs and relationships to force generation. Brain Res 1185:103-116. CrossRef Medline

Danion F, Latash ML, Li S (2003) Finger interactions studied with transcranial magnetic stimulation during multi-finger force production tasks. Clin Neurophysiol 114:1445-1455. CrossRef Medline

Dean HL, Hagan MA, Pesaran B (2012) Only coherent spiking in posterior parietal cortex coordinates looking and reaching. Neuron 73:829-841. CrossRef Medline

Diedrichsen J, Shadmehr R, Ivry RB (2010) The coordination of movement: optimal feedback control and beyond. Trends Cogn Sci 14:31-39. CrossRef Medline

Drew AS, van Donkelaar P (2007) The contribution of the human FEF and SEF to smooth pursuit initiation. Cereb Cortex 17:2618-2624. CrossRef Medline

Elsner C, D'Ausilio A, Gredebäck G, Falck-Ytter T, Fadiga L (2013) The motor cortex is causally related to predictive eye movements during action observation. Neuropsychologia 51:488-492. CrossRef Medline

Engel KC, Anderson JH, Soechting JF (2000) Similarity in the response of smooth pursuit and manual tracking to a change in the direction of target motion. J Neurophysiol 84:1149-1156. Medline

Engel KC, Soechting JF (2003) Interactions between ocular motor and manual responses during two-dimensional tracking. Prog Brain Res 142:141153. CrossRef Medline

Gagnon D, Paus T, Grosbras MH, Pike GB, O’Driscoll GA (2006) Transcranial magnetic stimulation of frontal oculomotor regions during smooth pursuit. J Neurosci 26:458-466. CrossRef Medline

Gauthier GM, Hofferer JM (1976) Eye tracking of self-moved targets in the absence of vision. Exp Brain Res 26:121-139. Medline

Gauthier GM, Vercher JL, Mussa Ivaldi F, Marchetti E (1988) Oculomanual tracking of visual targets: control learning, coordination control and coordination model. Exp Brain Res 73:127-137. CrossRef Medline

Gruet M, Temesi J, Rupp T, Millet GY, Verges S (2013) Effect of different approaches to target force on transcranial magnetic stimulation responses. Muscle Nerve 48:430-432. CrossRef Medline

Haarmeier T, Kammer T (2010) Effect of TMS on oculomotor behavior but not perceptual stability during smooth pursuit eye movements. Cereb Cortex 20:2234-2243. CrossRef Medline

Hiraoka K, Kurata N, Sakaguchi M, Nonaka K, Matsumoto N (2014) Interaction between the premotor processes of eye and hand movements: possible mechanism underlying eye-hand coordination. Somatosens Mot Res 31:49-55. CrossRef Medline

Huang CT, Hwang IS (2012) Eye-hand synergy and intermittent behaviors during target-directed tracking with visual and non-visual information. PLoS One 7:e51417. CrossRef Medline

Hwang EJ, Hauschild M, Wilke M, Andersen RA (2014) Spatial and temporal eye-hand coordination relies on the parietal reach region. J Neurosci 34:12884-12892. CrossRef Medline

Kawato M (1999) Internal models for motor control and trajectory planning. Curr Opin Neurobiol 9:718-727. CrossRef Medline

Landelle C, Montagnini A, Madelain L, Danion F (2016) Eye tracking a self-moved target with complex hand-target dynamics. J Neurophysiol 116:1859-1870. CrossRef Medline 
Maioli C, Falciati L, Gianesini T (2007) Pursuit eye movements involve a covert motor plan for manual tracking. J Neurosci 27:7168-7173. CrossRef Medline

Mehta B, Schaal S (2002) Forward models in visuomotor control. J Neurophysiol 88:942-953. Medline

Mills KR, Boniface SJ, Schubert M (1992) Magnetic brain stimulation with a double coil: the importance of coil orientation. Electroencephalogr Clin Neurophysiol 85:17-21. CrossRef Medline

Nuding U, Kalla R, Muggleton NG, Büttner U, Walsh V, Glasauer S (2009) TMS evidence for smooth pursuit gain control by the frontal eye fields. Cereb Cortex 19:1144-1150. CrossRef Medline

Ohtsuka K, Enoki T (1998) Transcranial magnetic stimulation over the posterior cerebellum during smooth pursuit eye movements in man. Brain 121:429-435. CrossRef Medline

Orban de Xivry JJ, Missal M, Lefèvre P (2008) A dynamic representation of target motion drives predictive smooth pursuit during target blanking. J Vis 8(6):1-13. CrossRef Medline

Passarelli L, Rosa MG, Gamberini M, Bakola S, Burman KJ, Fattori P, Galletti C (2011) Cortical connections of area V6Av in the macaque: a visualinput node to the eye/hand coordination system. J Neurosci 31:17901801. CrossRef Medline

Pincus SM (1991) Approximate entropy as a measure of system complexity. Proc Natl Acad Sci U S A 88:2297-2301. CrossRef Medline

Rossi S, Hallett M, Rossini PM, Pascual-Leone A (2009) Safety, ethical considerations, and application guidelines for the use of transcranial magnetic stimulation in clinical practice and research. Clin Neurophysiol 120:2008-2039. CrossRef Medline

Sailer U, Flanagan JR, Johansson RS (2005) Eye-hand coordination during learning of a novel visuomotor task. J Neurosci 25:8833-8842. CrossRef Medline

Scarchilli K, Vercher JL, Gauthier GM, Cole J (1999) Does the oculomanual co-ordination control system use an internal model of the arm dynamics? Neurosci Lett 265:139-142. CrossRef Medline

Scott SH (2004) Optimal feedback control and the neural basis of volitional motor control. Nat Rev Neurosci 5:532-546. CrossRef Medline

Steinbach MJ, Held R (1968) Eye tracking of observer-generated target movements. Science 161:187-188. CrossRef Medline

Timm J, SanMiguel I, Keil J, Schröger E, Schönwiesner M (2014) Motor intention determines sensory attenuation of brain responses to selfinitiated sounds. J Cogn Neurosci 26:1481-1489. CrossRef Medline

van Donkelaar P, Fisher C, Lee RG (1994) Adaptive modification of oculomotor pursuit influences manual tracking responses. Neuroreport 5:2233-2236. CrossRef Medline

Vercher JL, Quaccia D, Gauthier GM (1995) Oculo-manual coordination control: respective role of visual and non-visual information in ocular tracking of self-moved targets. Exp Brain Res 103:311-322. Medline

Vercher JL, Gauthier GM, Guédon O, Blouin J, Cole J, Lamarre Y (1996) Self-moved target eye tracking in control and deafferented subjects: roles of arm motor command and proprioception in arm-eye coordination. J Neurophysiol 76:1133-1144. Medline

Vercher JL, Sarès F, Blouin J, Bourdin C, Gauthier G (2003) Role of sensory information in updating internal models of the effector during arm tracking. Prog Brain Res 142:203-222. CrossRef Medline

Volz LJ, Hamada M, Rothwell JC, Grefkes C (2015) What makes the muscle twitch: motor system connectivity and TMS-induced activity. Cereb Cortex 25:2346-2353. CrossRef Medline

Voss M, Ingram JN, Haggard P, Wolpert DM (2006) Sensorimotor attenuation by central motor command signals in the absence of movement. Nat Neurosci 9:26-27. CrossRef Medline

Voss M, Bays PM, Rothwell JC, Wolpert DM (2007) An improvement in perception of self-generated tactile stimuli following theta-burst stimulation of primary motor cortex. Neuropsychologia 45:2712-2717. CrossRef Medline

Wassermann E, Epstein C, Ziemann U (2008) Oxford handbook of transcranial stimulation. Oxford: Oxford UP.

Wessel JR, Reynoso HS, Aron AR (2013) Saccade suppression exerts global effects on the motor system. J Neurophysiol 110:883-890. CrossRef Medline

Witham CL, Wang M, Baker SN (2010) Corticomuscular coherence between motor cortex, somatosensory areas and forearm muscles in the monkey. Front Syst Neurosci 4:38. CrossRef Medline

Wolpert DM, Flanagan JR (2010) Motor learning. Curr Biol 20:R467-R472. CrossRef Medline

Xu-Wilson M, Tian J, Shadmehr R, Zee DS (2011) TMS perturbs saccade trajectories and unmasks an internal feedback controller for saccades. J Neurosci 31:11537-11546. CrossRef Medline 